\title{
Topology Optimized Mode Conversion In a Photonic Crystal Waveguide
}

\author{
Frandsen, Lars Hagedorn; Elesin, Yuriy; Ding, Yunhong; Sigmund, Ole; Yvind, Kresten
}

Published in:

2013 IEEE Photonics Conference (IPC)

Link to article, DOI:

10.1109/IPCon.2013.6656572

Publication date:

2013

Link back to DTU Orbit

Citation (APA):

Frandsen, L. H., Elesin, Y., Ding, Y., Sigmund, O., \& Yvind, K. (2013). Topology Optimized Mode Conversion In a Photonic Crystal Waveguide. In 2013 IEEE Photonics Conference (IPC) (pp. 333-334). IEEE.

https://doi.org/10.1109/IPCon.2013.6656572

\section{General rights}

Copyright and moral rights for the publications made accessible in the public portal are retained by the authors and/or other copyright owners and it is a condition of accessing publications that users recognise and abide by the legal requirements associated with these rights.

- Users may download and print one copy of any publication from the public portal for the purpose of private study or research.

- You may not further distribute the material or use it for any profit-making activity or commercial gain

- You may freely distribute the URL identifying the publication in the public portal

If you believe that this document breaches copyright please contact us providing details, and we will remove access to the work immediately and investigate your claim. 


\title{
Topology Optimized Mode Conversion In a Photonic Crystal Waveguide
}

\author{
Lars H. Frandsen¹, Yuriy Elesin², Yunhong Ding', Ole Sigmund², and Kresten Yvind ${ }^{1}$ \\ ${ }^{1}$ DTU Fotonik, Department of Photonics Engineering, Technical University of Denmark, DK-2800 Lyngby, Denmark \\ ${ }^{2}$ DTU Mekanik, Department of Mechanics Engineering, Technical University of Denmark, DK-2800 Lyngby, Denmark
}

\begin{abstract}
We experimentally demonstrate an ultra-compact $\mathrm{TE}_{0}-\mathrm{TE}_{1}$ mode converter obtained in a photonic crystal waveguide by utilizing topology optimization and show a $\sim 39 \mathrm{~nm}$ bandwidth around $1550 \mathrm{~nm}$ with an insertion loss lower than $\sim 3 \mathrm{~dB}$.
\end{abstract}

Mode conversion in ultra-compact photonic integrated circuits (PICs) has recently been investigated $[1,2,3]$ to support on-chip processing of mode-division multiplexed data-signals. Typically, integrated mode converters rely on phase detuning between waveguides in an interferometric configuration [1] or scattering effects induced in single waveguides [2,3]. The approach based on phase detuning gives a compact and efficient solution for conversion between the fundamental even and the first order odd modes, but requires a large size of the device for doing higher order conversions [4], which makes it a less attractive choice for dense PICs handling several mode orders. On the other hand, mode converters based on scattering effects topologically induced in the waveguide may have footprints of a few square vacuum wavelengths, but have problems of being realized in practice due to the delicacy of the scatters.

Topology optimization (TO) [5] has so far been proven to be a strong and robust inverse design tool for designing various compact nanophotonic components with broadband and low-loss performances [6]. Here, we present the first experimental results for low-loss $\mathrm{TE}_{0}-\mathrm{TE}_{1}$ mode conversion in a topology optimized photonic crystal waveguide (PhCW) fabricated in silicon-on-insulator (SOI) material and demonstrate the practical feasibility of using TO to realize ultra-compact mode conversion in PICs.

The initial PhCW design shown in Fig. 1(a) is formed by air holes (black) with diameter $\mathrm{D}=0.6 \Lambda$ in silicon (white) where $\Lambda=420 \mathrm{~nm}$ is the pitch of the triangular lattice. The diameter of the second row of holes has been increased to $\mathrm{D}_{2}=0.8 \Lambda$ to make the first order transverse electric odd mode $\left(\mathrm{TE}_{1}\right)$ nondegenerate in the wavelength region of interest. The objective of the TO is to convert the fundamental transverse electric even $\left(\mathrm{TE}_{0}\right)$ mode (Fig. 1(b)) of the $\mathrm{PhCW}$ into the $\mathrm{TE}_{1}$ mode (Fig. 1(c)) in a $40 \mathrm{~nm}$ wavelength region located in the index-guided regime of the $\mathrm{PhCW}$ around $1550 \mathrm{~nm}$.



(a)

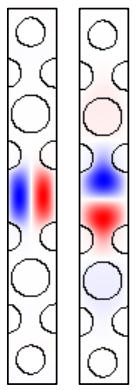

(b) (c)

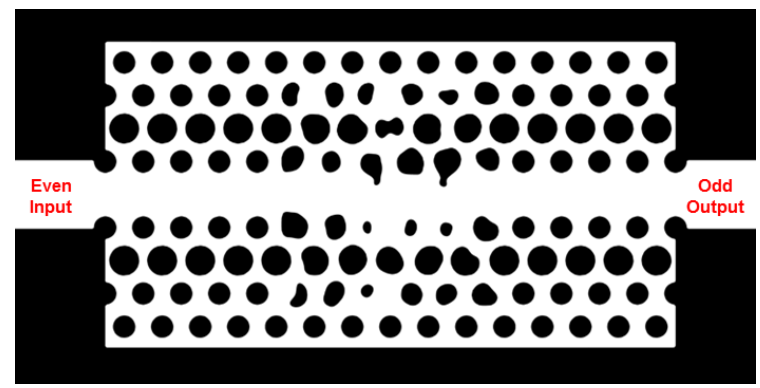

(d)

Fig. 1. (a) Initial design of the PhCW defined by air holes (black) arranged in a triangular lattice in silicon (white). Also shown is the design domain (green) chosen in the TO. $2 \mathrm{D}$ mode plots for the (b) $\mathrm{TE}_{0}$ and (c) $\mathrm{TE}_{1}$ mode of the $\mathrm{PhCW}$. (d) Topology optimized mode converter design obtained by utilizing 2D TO.

TO is performed utilizing 2D finite-difference time-domain (FDTD) modelling using a software package developed in-house. The optimization process is based on repeated solutions of the state and the adjoint equations and design updates [7]. The design domain (green areas in Fig. 1(a)) was intuitively 
specified as a set of regions around the 3 innermost rows of holes in order to prevent dramatic changes in the design and to avoid appearance of silicon islands. A converged topology optimized design with a $\mathrm{TE}_{0} / \mathrm{TE}_{1}$ extinction ratio better than $-12 \mathrm{~dB}$ is obtained after $\sim 100$ optimization steps and the final design is shown in Fig. 1(d).
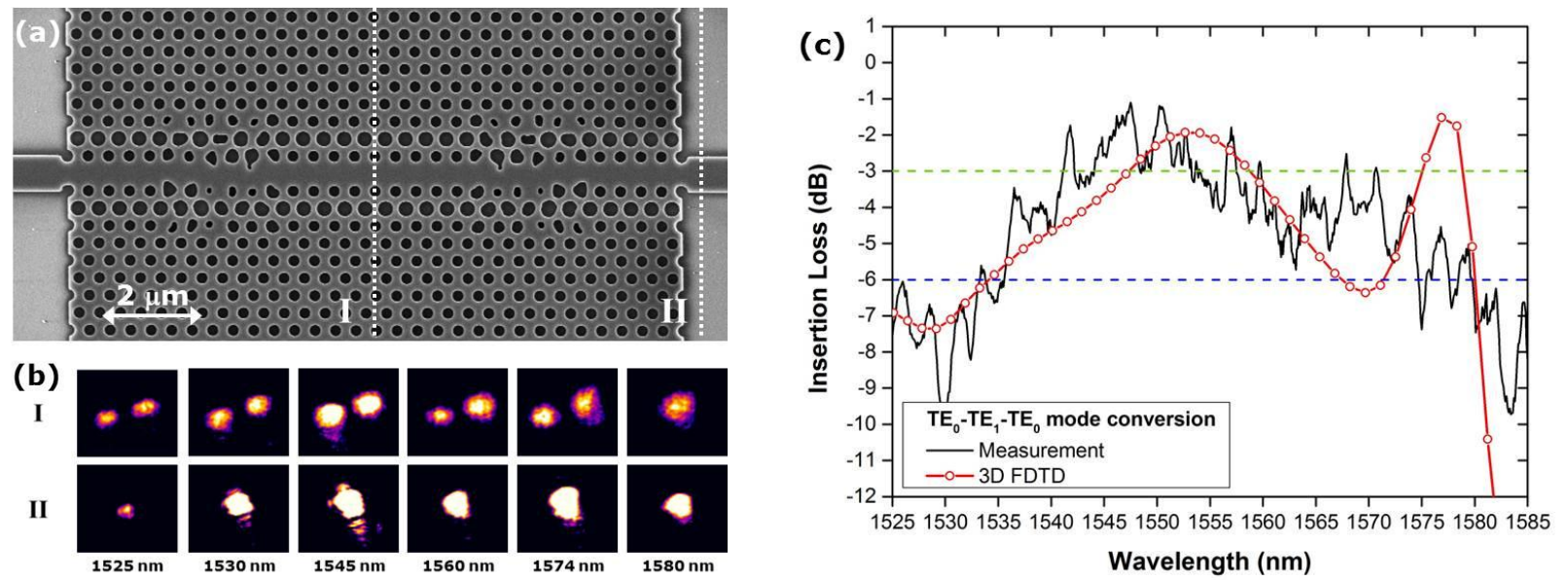

Fig. 2. (a) SEM image of the optimized $\mathrm{TE}_{0}-\mathrm{TE}_{1}-\mathrm{TE}_{0}$ mode converter fabricated for characterization purpose in SOI material. (b) Mode profiles recorded for the $\mathrm{TE}_{0}-\mathrm{TE}_{1}$ (I) and $\mathrm{TE}_{0}-\mathrm{TE}_{1}-\mathrm{TE}_{0}$ (II) mode converters at given wavelengths. (c) Measured (black) and 3D FDTD calculated (red) insertion loss for the device.

For characterization purposes, both a $\mathrm{TE}_{0}-\mathrm{TE}_{1}$ and a $\mathrm{TE}_{0}-\mathrm{TE}_{1}-\mathrm{TE}_{0}$ mode converter were realized. The latter was done by mirroring the $\mathrm{TE}_{0}-\mathrm{TE}_{1}$ converter subsequently after the $\mathrm{TE}_{0}-\mathrm{TE}_{1}$ conversion. Figure 2(a) shows a scanning electron micrograph (SEM) image of the $\mathrm{TE}_{0}-\mathrm{TE}_{1}-\mathrm{TE}_{0}$ mode converter fabricated in SOI material. Mode field profiles corresponding to positions I and II in Fig. 2(a) are recorded on an infrared camera by use of vertical grating couplers [8] placed after the $\mathrm{TE}_{0}-\mathrm{TE}_{1}$ and the $\mathrm{TE}_{0}-\mathrm{TE}_{1}-\mathrm{TE}_{0}$ mode converters. Figure 2(b) shows the recorded output field profiles for the $\mathrm{TE}_{0}-\mathrm{TE}_{1}(\mathrm{I})$ and $\mathrm{TE}_{0^{-}}-\mathrm{TE}_{1^{-}}$ $\mathrm{TE}_{0}$ (II) converters for $\mathrm{TE}_{0}$ light input, clearly demonstrating that the $\mathrm{TO}$ design converts light from the $\mathrm{TE}_{0}$ to the $\mathrm{TE}_{1}$ mode and back in a $\sim 49 \mathrm{~nm}$ wavelength region from $\sim 1525 \mathrm{~nm}$ to $\sim 1574 \mathrm{~nm}$. Figure 2(c) shows the measured (black) and 3D FDTD calculated (red) insertion loss as a function of wavelength for the $\mathrm{TE}_{0}-\mathrm{TE}_{1}-\mathrm{TE}_{0}$ mode converter. An insertion loss better than $6 \mathrm{~dB}$ is experimentally seen in the wavelength region from $\sim 1535 \mathrm{~nm}$ to $\sim 1574 \mathrm{~nm}$ with a minimum insertion loss of $\sim 1.5 \mathrm{~dB}$, which is in good agreement with 3D FDTD calculations. For the $\mathrm{TE}_{0}-\mathrm{TE}_{1}$ converter the insertion loss can be halved, experimentally demonstrating an efficient conversion of the $\mathrm{TE}_{0}$ to the $\mathrm{TE}_{1}$ mode with an insertion loss lower than $3 \mathrm{~dB}$ in a $\sim 39 \mathrm{~nm}$ bandwidth. We believe that the TO method can easily be applied to realize low-loss conversions between higher order modes with complex mode fields in PhCWs or photonic wires.

[1] Y. Huang, G. Xu, and S.-T. Ho, “An ultracompact optical mode order converter,” IEEE Photon. Technol. Lett., Vol. 18, No. 21, pp. 2281-2283 (2006).

[2] V. Liu, D. A. B. Miller, and S. Fan, "Ultra-compact photonic crystal waveguide spatial mode converter and it's connection to the optical diode effect," Opt. Express, Vol. 20, No. 27, pp. 28388-28397 (2012).

[3] J. Lu and J. Vǔcković, "Objective-first design of high-efficiency, small-footprint couplers between arbitrary nanophotonic waveguide modes," Opt. Express, Vol. 20, No. 7, pp. 7221-7236 (2012).

[4] B.-T. Lee and S.-Y. Shin, "Mode-order converter in a multimode waveguide," Opt. Lett., vol. 28, 18, pp. 1660-1662 (2003).

[5] M. P. Bendsøe and N. Kikuchi, "Generating optimal topologies in structural design using a homogenization method,"

Comput. Meth. Appl. Mech. Engng. 71, pp. 197-224 (1988).

[6] J.S. Jensen, O. Sigmund, "Topology optimization for nano-photonics," Laser \& Photonics Reviews, Vol. 5, 2, p. 308 (2011).

[7] Y. Elesin, B.S. Lazarov, J.S. Jensen and O. Sigmund. "Design of robust and efficient photonic switches using topology optimization," Photonics and Nanostructures - Fundamentals and Applications 10 (2012).

[8] Y. Ding, H. Ou, J. Xu, M. Xiong, and C. Peucheret, "On-chip Mode Multiplexer Based on a Single Grating Coupler," Proceedings of IEEE Photonics Conference (IPC), pp. 707-708 (2012).

\section{Acknowledgments}

This work was supported by the VILLUM foundation via the project 'Optical Nano-engineered Components for High-capacity Integrated silicon Photonics' (ONCHIP) and 'Nanophotonics for Terabit Communications' (NATEC) centre of excellence. 